\title{
Day-to-Day Variability of H Component of Geomagnetic Field in Central African Sector Provided by Yaoundé-Cameroon Amber Station
}

\author{
Messanga Etoundi Honore, Kosh Djaka Comelo, Mbane Biouele Cesar* \\ Laboratory of Earth's Atmosphere Physics, Department of Physics, University of Yaoundé I, Yaoundé, \\ Cameroun \\ Email: ${ }^{*}$ cesar.mbane@yahoo.fr
}

Received 16 June 2014; revised 12 July 2014; accepted 5 August 2014

Copyright (C) 2014 by authors and Scientific Research Publishing Inc.

This work is licensed under the Creative Commons Attribution International License (CC BY). http://creativecommons.org/licenses/by/4.0/

(c) $\underset{\mathrm{EY}}{\mathrm{EY}}$ Open Access

\section{Abstract}

The geomagnetic data obtained from Amber Network station in Cameroon have been used for this study. The variability of $\mathrm{H}$ component of geomagnetic field has been examined by using geomagnetic field data of $X$ and $Y$ components recorded at AMBER magnetometer station hosted by the Department of Physics of University of Yaoundé $\left(3.87^{\circ} \mathrm{N}, 11.52^{\circ} \mathrm{E}\right)$. The day-to-day variability of the horizontal intensity of the geomagnetic field was examined and shows that the scattering of $H$ component of magnetic field variation is more on disturbed than that on quiet condition. The signatures $\mathrm{H}$ of geomagnetic Sq and Sd variations in intensities in the geomagnetic element, has been studied. This study shows that the daytime variations in intensities of geomagnetic elements $\mathrm{H}$, $\mathrm{Sq}(\mathrm{H})$ and $\mathrm{Sd}(\mathrm{H})$ respectively are generally greater than night-time ones. This paper interests answering the two questions: 1) how can geomagnetic variations be used to study the equatorial ionosphere electrodynamics and electrojet equatorial over Africa in general and Cameroon in particular? 2) How can geomagnetic variations be used to monitor and predict space weather events in Cameroon? This paper presents and interprets the results of $\mathrm{H}$ component of geomagnetic field variations during magnetic storms and on quiet days.

\section{Keywords}

Geomagnetic Field, AMBER Magnetometer Station, Magnetic Storms, Equatorial Electrojet

\footnotetext{
${ }^{*}$ Corresponding author.
} 


\section{Introduction}

Through a cooperative program with the United Nations Basic Space Science (UNBSS) program, the IHY/ISWI has facilitated the deployment of a number of arrays of small instruments to make global measurements of space-physics-related phenomena. The African Meridian B field Education and Research (AMBER) magnetometer array is one of the ground-based instruments deployed in Africa under the IHY program [1]. The AMBER array contains fifteen magnetometers (either deployed or in the process of deployment) and spans across Africa, Asia and Brazil beneath the geomagnetic equator from the $L$ of 1.0 to an $L$ of 1.4. One of the objectives of the AMBER array is to address the processes that govern the electrodynamics of the equatorial ionosphere in the African sector and compare and contrast with electrodynamics in other longitudinal sectors. Similarly, the Low Latitude Ionospheric Sensor Network (LISN) project [2] has been instrumental in deploying five magnetometers in the Peruvian and west Brazilian sector along the geomagnetic equator. The magnitude and direction of the dayside vertical velocity $(\mathrm{E} \times \mathrm{B}$ drift) can be easily estimated using pairs of ground magnetometers around the dip equator [3]-[6]. The equatorial electrojet current (EEJ) produces a strong enhancement in the $\mathrm{H}$ component magnetic field measured by magnetometers located within \pm 3 _ of the magnetic equator. In principle, measuring this perturbation in equatorial magnetometers could provide a direct measure of the EEJ. However, ground magnetometers respond to all currents within their field of view. Equatorial stations respond primarily to the EEJ, which is directly overhead, but also to the ring current and the global quiet time Sq current system. The typical extent of the EEJ is within \pm 3 _ of the dip equator. Ground magnetometers just outside the extent of the EEJ, 6_-9_ off the dip equator, would exhibit near-zero response to the EEJ, but have the same response to the ring and Sq currents as an equatorial station. The ring current and global Sq dynamo contribution to the $\mathrm{H}$ component can then be removed by taking the difference between the $\mathrm{H}$ component recorded at the magnetic equator and off the equator (_6-9_ geomagnetic). The difference is the only part of the $\mathrm{H}$ component field that is related to the EEJ current contribution which, in turn, is directly related to the east-west electric field. Therefore, the $\mathrm{E} \times$ B drift can be estimated using the resulting difference $(1 \mathrm{H})$ value of the $\mathrm{H}$ component field [3]. To avoid different offset values of different magnetometers, the nighttime baseline values in the $\mathrm{H}$ component are first obtained for each day and subtracted from the corresponding magnetometer data sets. This provides the variation of daytime $\mathrm{H}$ component values of each magnetometer.

\section{Data Analysis}

For this study the magnetometer that has been used for $\mathrm{H}, \mathrm{Sq}(\mathrm{H})$ and $\mathrm{Sd}(\mathrm{H})$ observation and thus estimation of magnetic storms days, and African Amber magnetometers immediately around are given in Table 1. The geographic locations of these magnetometers are shown in Figure 1. The data set used in this analysis consists of minute values of geomagnetic elements, northward component $\mathrm{X}$, and eastward component $\mathrm{Y}$, recorded at the

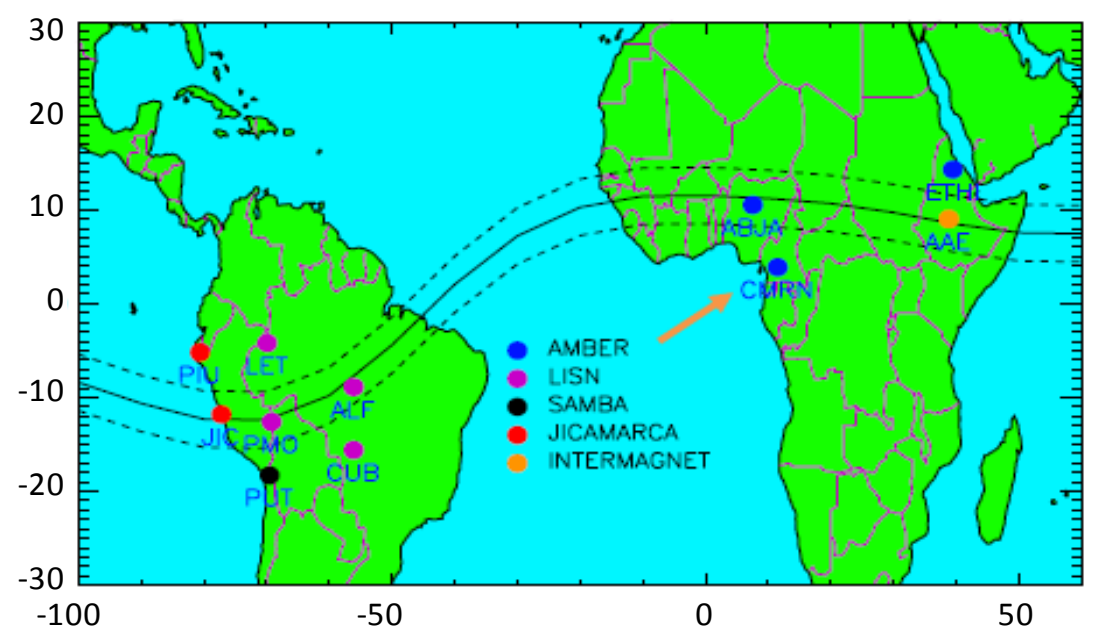

Figure 1. Geographic location of the Amber ground-based magnetometer used for this study. The solid horizontal line depicts the geomagnetic equator, and the two dashed lines indicate the EEJ region. 
Table 1. List of well performing African Amber magnetometer stations.

\begin{tabular}{ccccccc}
\hline Station name & Station code & Project it belongs to & Geog. Lat. & Geog. Lon. & Geom. Lat. & Geom. Lon. \\
\hline Adigrat & ETHI & AMBER & $14.3^{\circ} \mathrm{N}$ & $39.5^{\circ} \mathrm{E}$ & $6.0^{\circ} \mathrm{N}$ & $111.1^{\circ} \mathrm{E}$ \\
Abuja & ABJA & AMBER & $10.5^{\circ} \mathrm{N}$ & $7.55^{\circ} \mathrm{E}$ & $0.6^{\circ} \mathrm{N}$ & $79.6^{\circ} \mathrm{E}$ \\
Yaounde & CMRN & AMBER & $3.9^{\circ} \mathrm{N}$ & $11.5^{\circ} \mathrm{E}$ & $5.8^{\circ} \mathrm{S}$ & $83.1^{\circ} \mathrm{E}$ \\
\hline
\end{tabular}

Yaoundé AMBER Observatory sheltered by the Department of Physics, University of Yaoundé 1 throughout the year 2011. The quiet or disturbed days are those universally recognized by the World Data Center (WDR).

Our observatory provides the magnetic data in the XYZ coordinates system such as defined by Campbell [7]. By simple geometry, the conversion from $\mathrm{X}$ and $\mathrm{Y}$ to $\mathrm{H}$ is obtained from (1):

$$
\mathrm{H}=\sqrt{\mathrm{X}^{2}+\mathrm{Y}^{2}} \text {. }
$$

The method of analysis that we use in this work has already used by several authors [8]-[10]. The minutely data was converted to hourly data in this work.

\subsection{Determination of the Baseline Value $\mathrm{H}_{0}$}

The local time was used throughout the analysis. The observatory is 1 hour ahead of the Greenwich Mean Time and thus, when it is 11.00 a.m. Universal Time (UT) is 12 noon Local Time (LT). The local daily baseline value $\mathrm{H}_{0}$ (Equation (2)) of geomagnetic field each day of the year was obtained by calculating the average value of the data of the 4 hours flanking local midnight (23, 00, 01, 02 hours).

$$
\mathrm{H}_{0}=\frac{\mathrm{H}_{23}+\mathrm{H}_{00}+\mathrm{H}_{01}+\mathrm{H}_{02}}{4}
$$

where $\mathrm{H}_{23}, \mathrm{H}_{00}, \mathrm{H}_{01}$ and $\mathrm{H}_{02}$ are the hourly values of $\mathrm{H}$ at 23, 00, 01 and 02 hours LT respectively.

\subsection{Evaluation of Hourly Departure}

The hourly departure of $\mathrm{H}$ for each day in relation to its local midnight value of day under consideration was obtained by subtracting the daily baseline value for each day from the hourly data for that particular day. That is

$$
\mathrm{dH}(t)=\mathrm{H}(t)-\mathrm{H}_{0}
$$

where $t=0$ to $23 \mathrm{hrs}$.

\subsection{Correction for Non-Cyclic Variation}

The non-cyclic variation $\left(\mathrm{H}_{c}\right)$ defined as a phenomenon in which the value at $01 \mathrm{LT}$ is different from the value at 00 LT was removed [11]-[15].

$$
\mathrm{H}_{c}=\frac{\mathrm{dH}_{0}-\mathrm{dH}_{23}}{23}
$$

The linearly adjusted values at these hours are:

$$
\sum_{i=0}^{i=23} \mathrm{dH}_{i}+i . \mathrm{H}_{c}
$$

in other words,

$$
\mathrm{Sq}_{t}(\mathrm{H})=\mathrm{dH}_{t}+t \mathrm{H}_{c}
$$

where $t$ is the local time ranging from 0 to 23 .

The hourly departures correction for non-cyclic variation gives the solar daily variation in $\mathrm{H}$. $\mathrm{Sq}(\mathrm{H})$ denote the solar quiet daily variation in $\mathrm{H}$; while $\mathrm{Sd}(\mathrm{H})$ denote the solar disturbance daily variation in $\mathrm{H}$. 


\section{Observations}

\subsection{Geomagnetic Storms and Disturbances Days during 2011's Campaign}

On Figures 2-7 below are plotted the amplitude of geomagnetic field component $\mathrm{dH}$ [nT] and then identification of the main disturbed and stormy days observed on Yaoundé-Cameroon (YACM) during the 2011's campaign. On various figures: green color indicates quiet day; yellow color indicates disturbed days and red color indicates stormy days. It appears clearly that, the quiet condition and disturbed condition occur in the $\mathrm{H}$ component of geomagnetic field throughout the year. The daily variation of $\mathrm{H}$ starts mounting between 06 hrs (LT), reaches the peak at about 12 noon, and reclines to low level at 18 hrs LT. In general, the day-time magnitudes are much greater than the night time magnitudes throughout the year. This variation pattern is due to the diurnal variation of the ionospheres' conductivity [16]-[20].
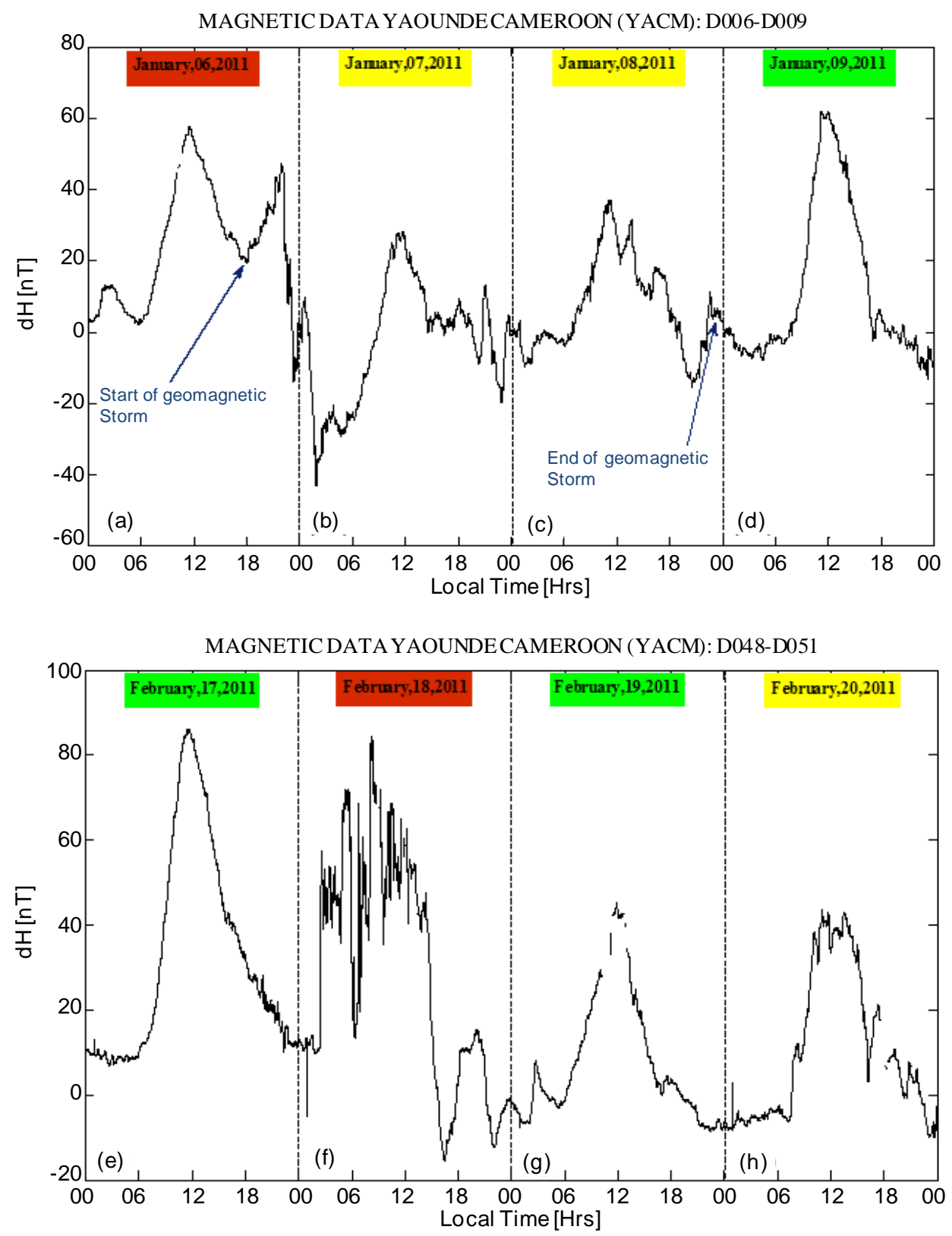

Figure 2. Geomagnetic storms and disturbances days during 2011's campaign: from Day [6] to Day [51]. 
MAGNETIC DATA YAOUNDECAMEROON (YACM): D060-D063

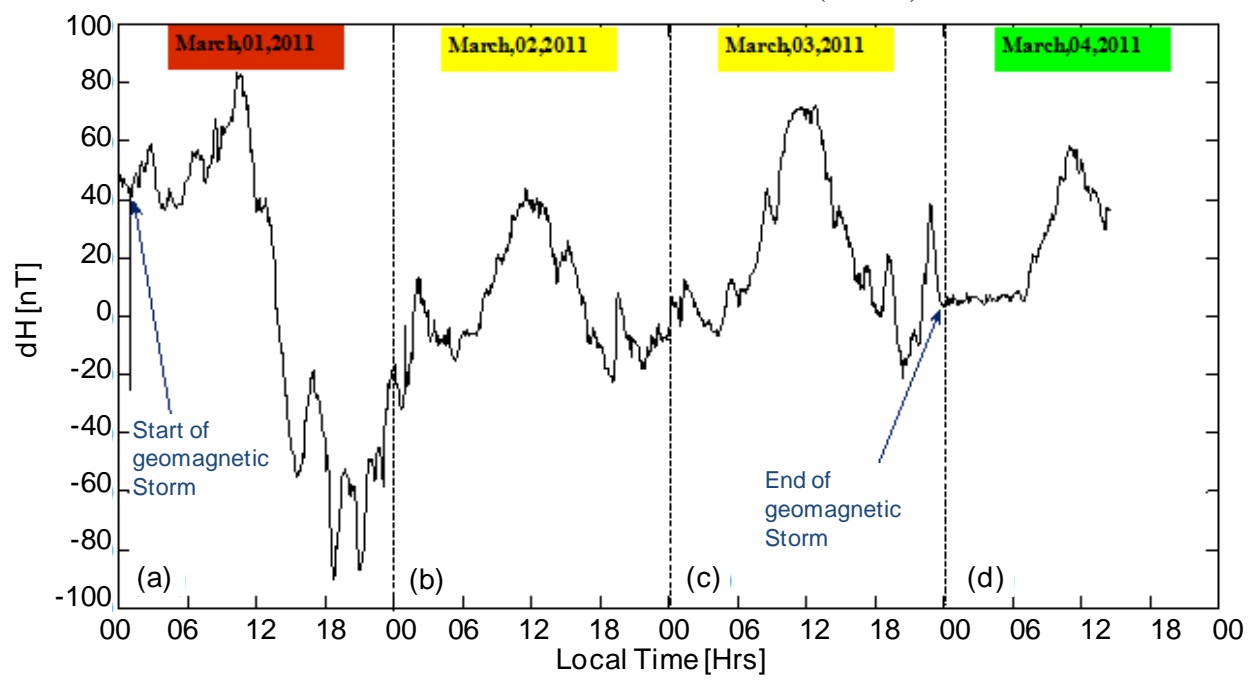

MAGNETIC DATA YAOUNDE CAMEROON (YACM): D068-D071
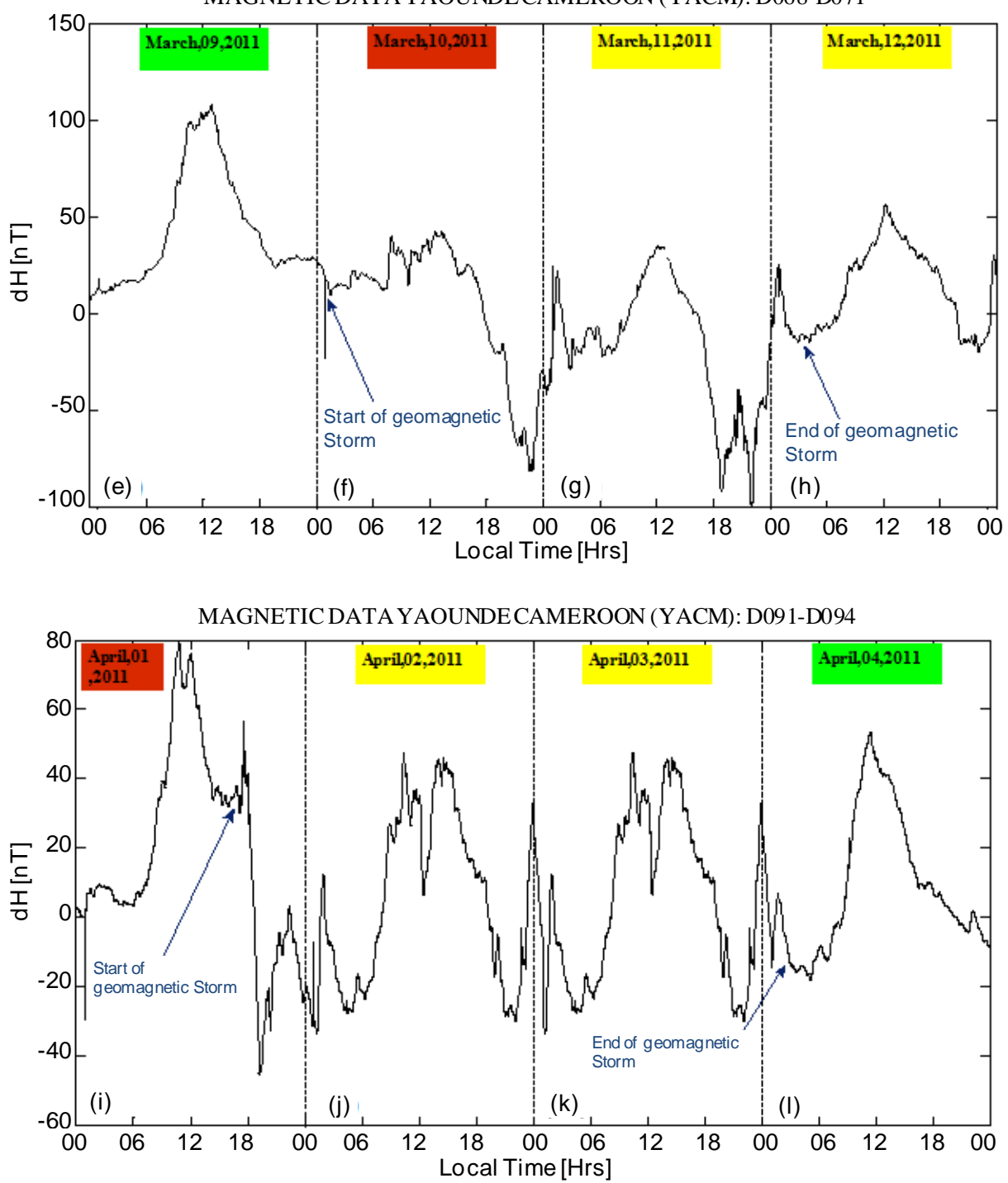


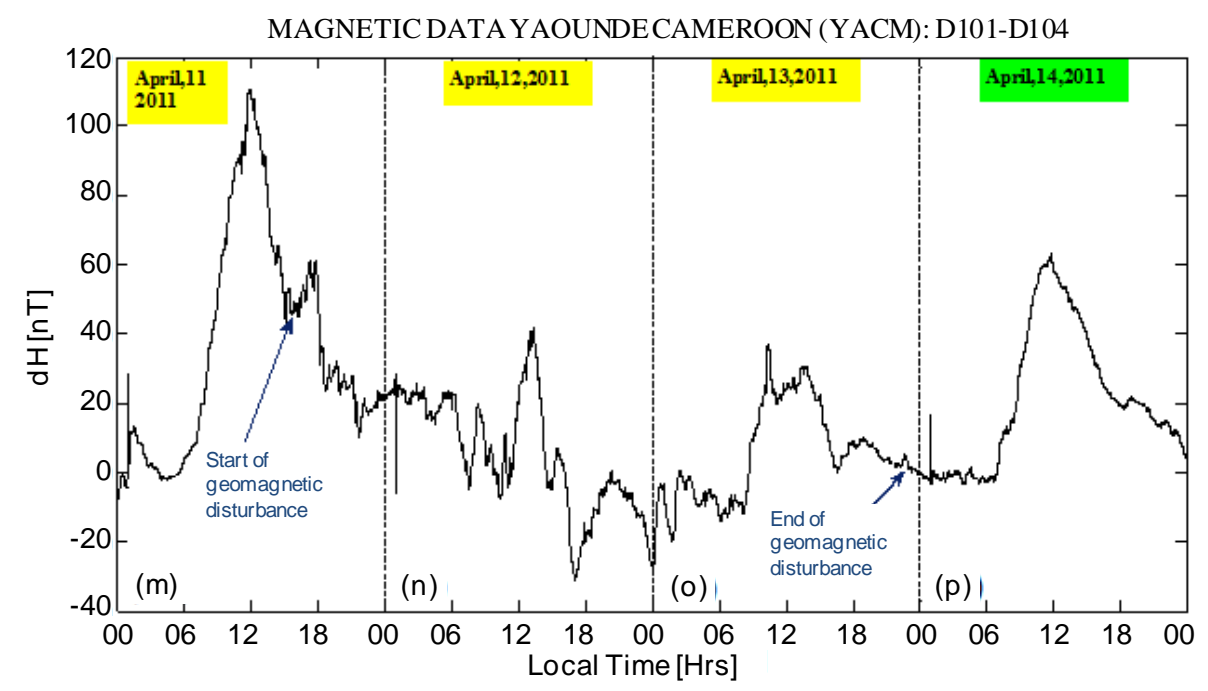

Figure 3. Geomagnetic storms and disturbances days during 2011’s campaign: from Day [60] to Day [104].
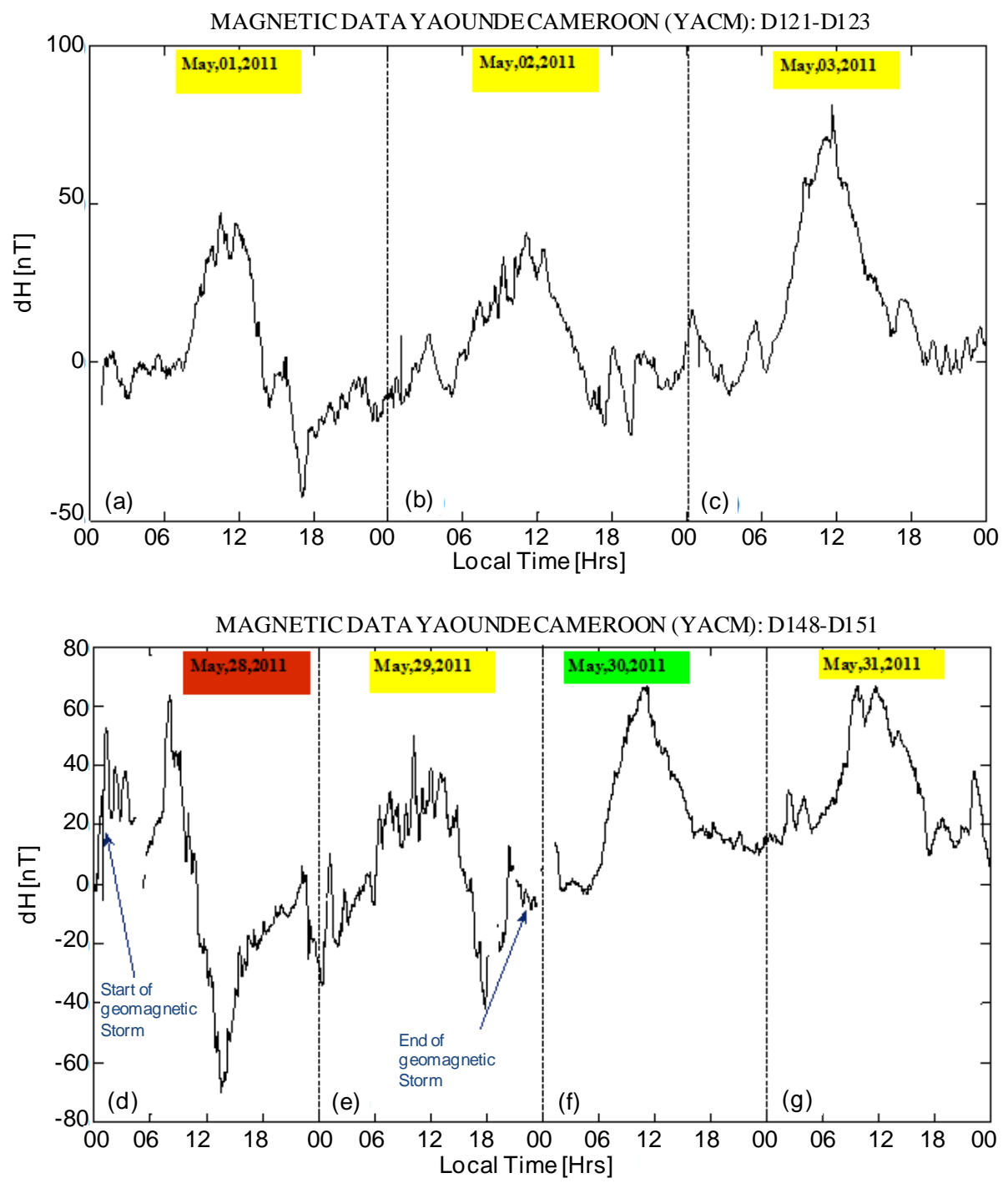

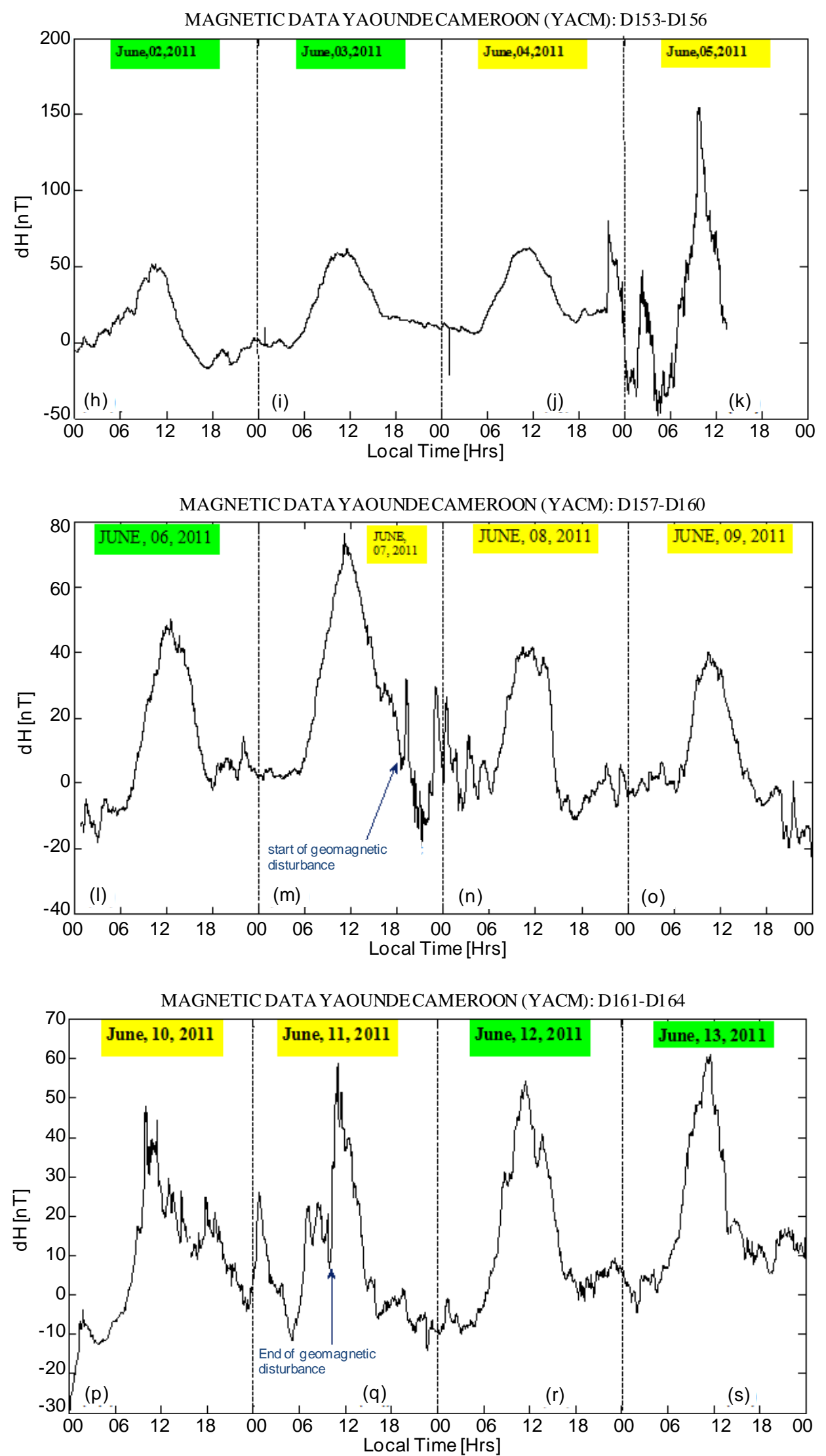
MAGNETIC DATA YAOUNDECAMEROON (YACM): D171-D174

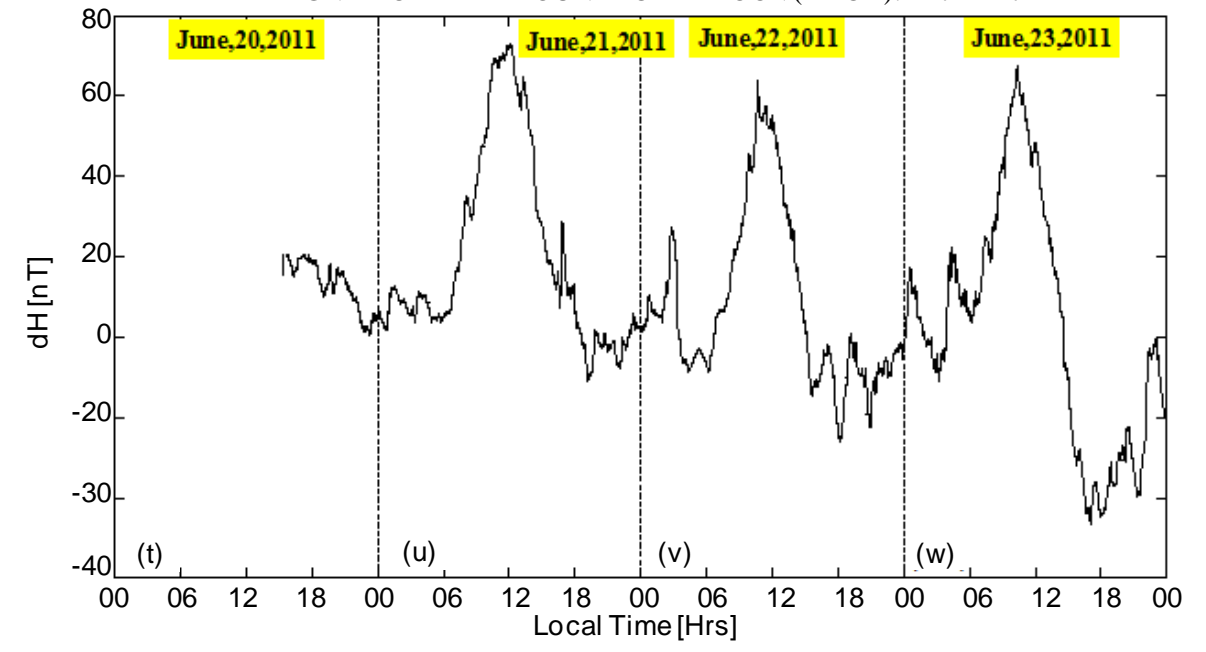

Figure 4. Geomagnetic storms and disturbances days during 2011’s campaign: from Day [121] to Day [174].
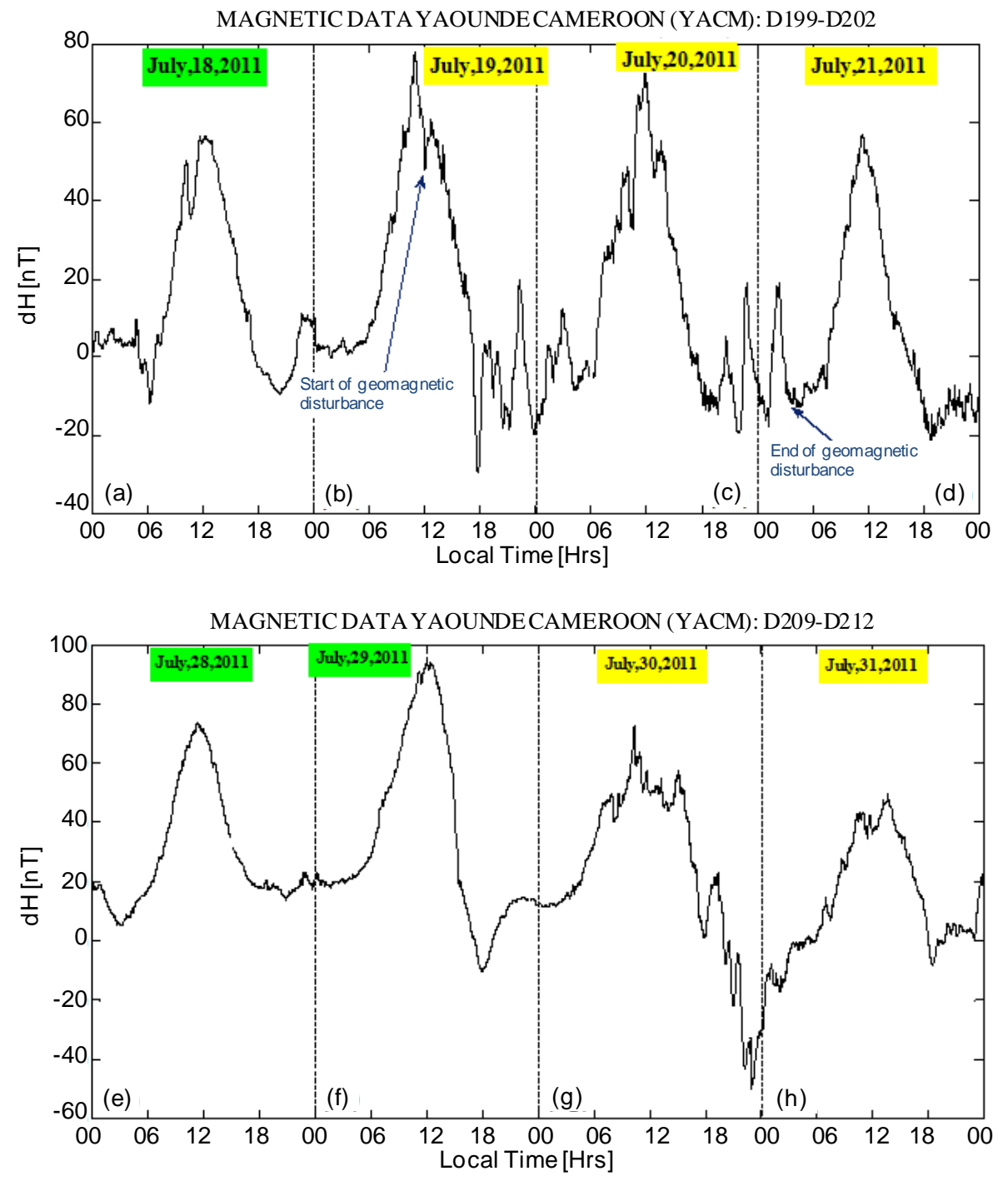


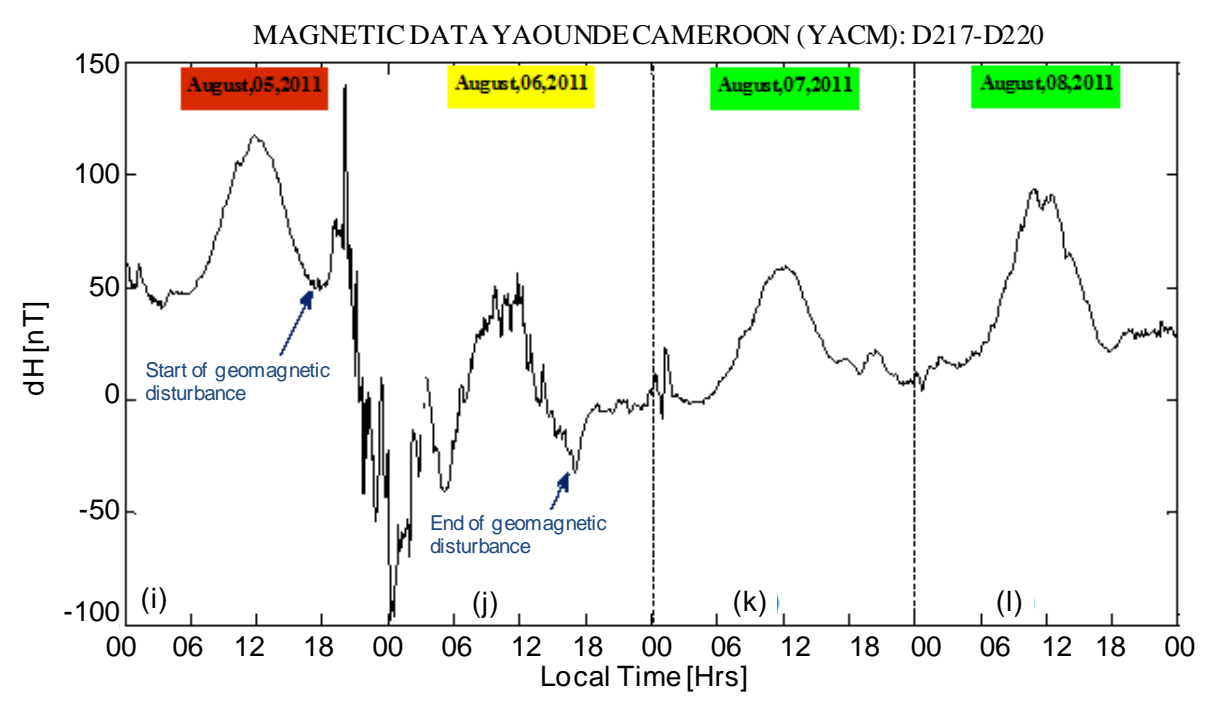

Figure 5. Geomagnetic storms and disturbances days during 2011's campaign: from Day [199] to Day [220].
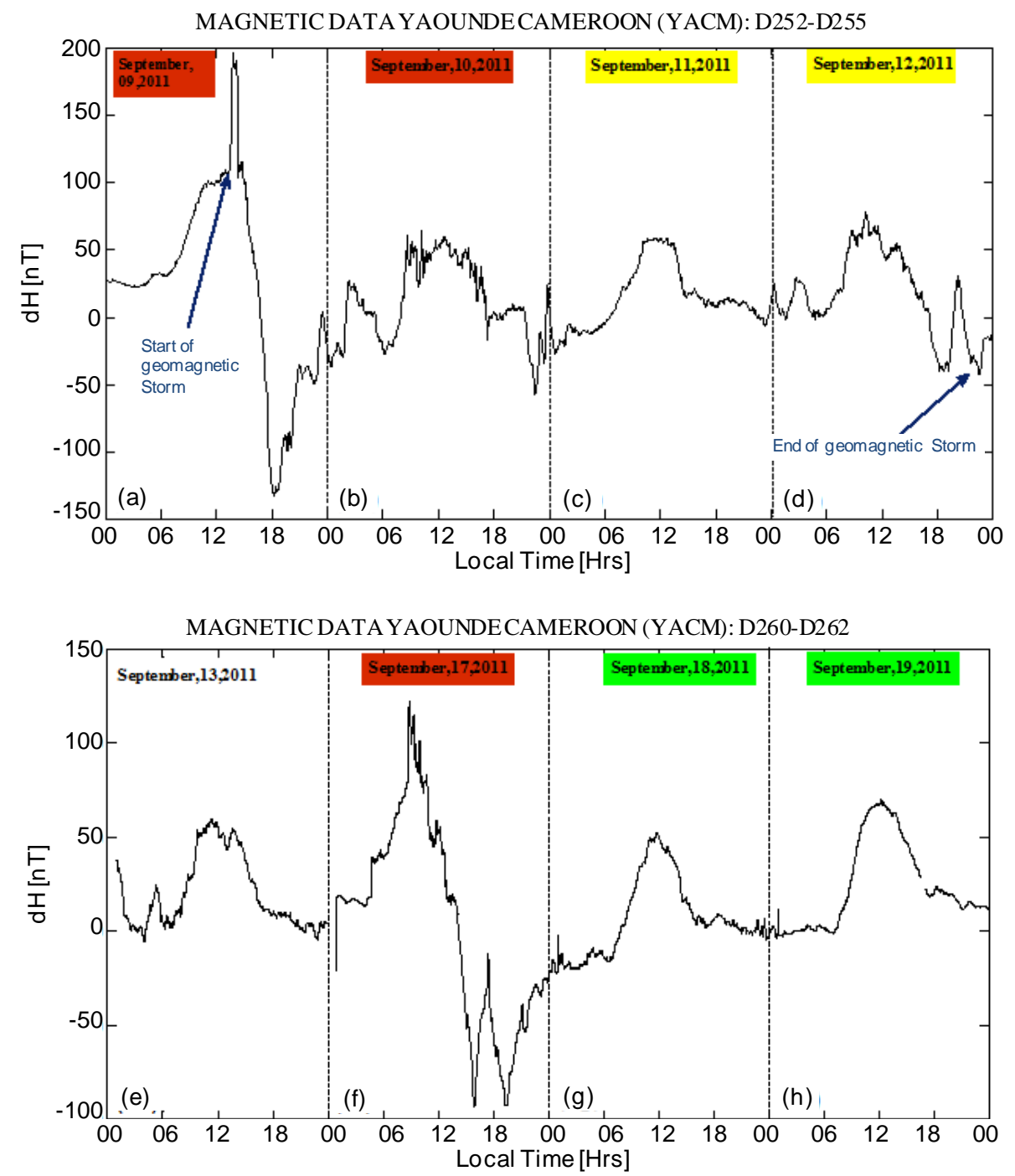


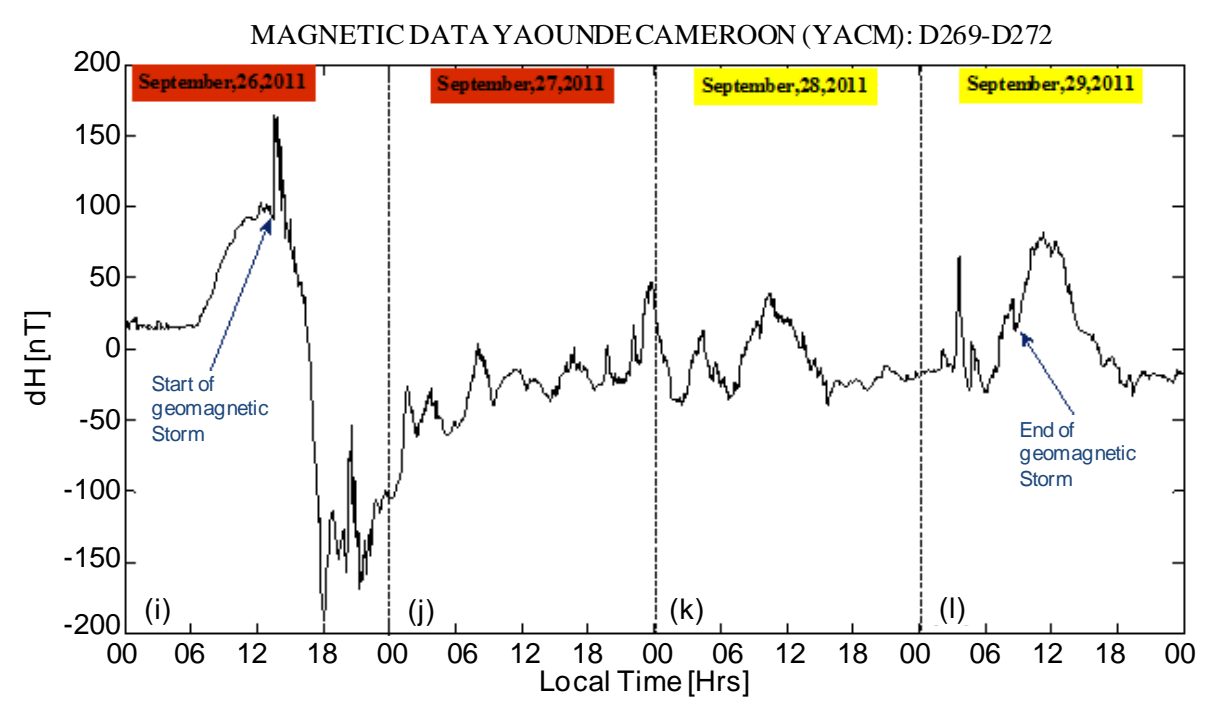

Figure 6. Geomagnetic storms and disturbances days during 2011’s campaign: from Day [252] to Day [272].
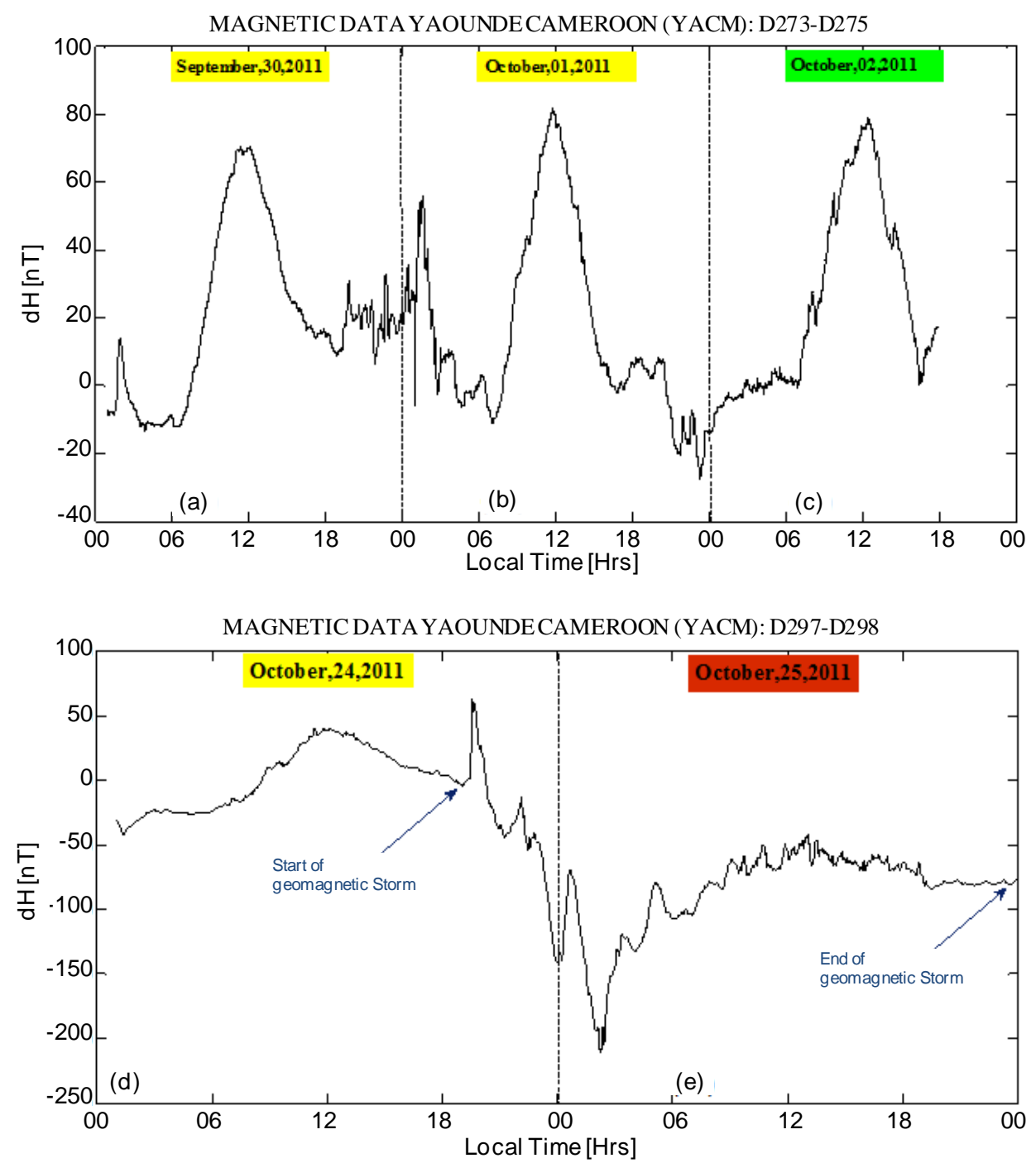

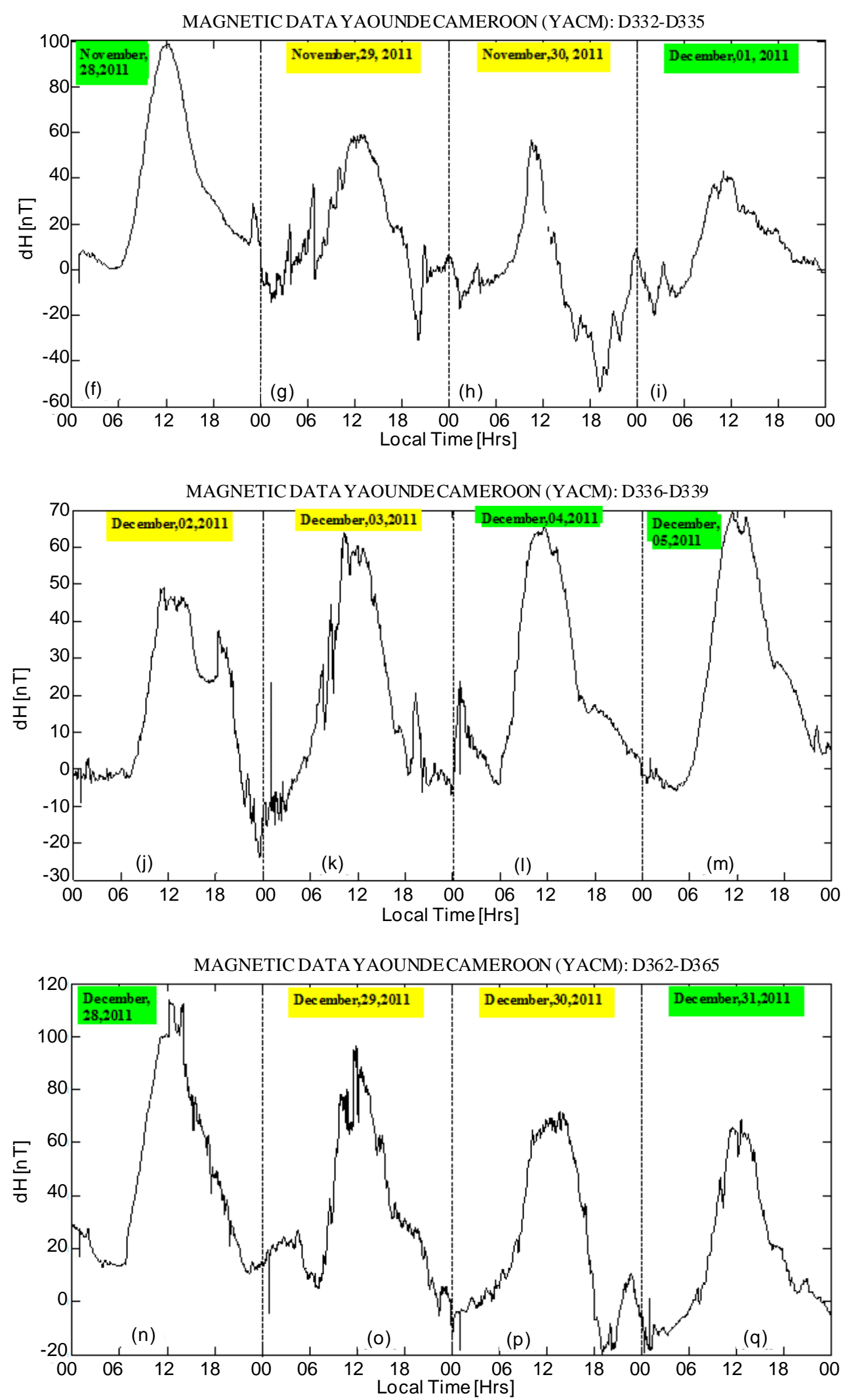

Figure 7. Geomagnetic storms and disturbances days during 2011’s campaign: from Day [273] to Day [365]. 
However, this variation pattern can be affected during magnetic storms, during which the Earth's geomagnetic field experiences a huge input of charged energetic particles from the sun into the Earth's magnetosphere. Or during magnetic recombination when the sun's magnetic field stretches far out into the interplanetary medium and directly link with the Earth's magnetic field. This explains the fact that one attends a strongly reducing of the amplitude of $\mathrm{H}$ component of geomagnetic field between 06 - 12 hrs LT instead of increasing in this one; or then an abrupt increasing between 18 - 24 hrs LT instead of decreasing, it is the case for example on Figure 5(a) and Figure 6(d) (April 01 and May 28) which illustrates this phenomenon well.

From Figure 2 to Figure 7, main geomagnetic storms for 2011 were observed to occur on the following dates: January 06; February 18; March (01; 10); April 01; May 28; August 05; September (09; 10; 17; 27; 28) and October 25. Each geomagnetic storm is characterized by three major phases. These are: the initial phase, the main phase and the recovery phase. The initial phase is characterized by sudden commencement or a step increase of $\mathrm{H}$. In the main phase, the amplitude of geomagnetic field component $\mathrm{H}(\mathrm{dH})$ falls to values between $100-1000$ $\mathrm{nT}$ depending on the severity of the storm. In the recovery phase, the geomagnetic field states increasing and finally returns to its pre-storm state between two to three days. A geomagnetic storm can be characterized by rapid fluctuations of geomagnetic field which can induce GIC (Geomagnetically Induced Currents) in technological systems, affect radio waves travelling through the ionosphere (Scintillation) as well as produce beautiful auroras in mid-latitudes.

\subsection{Diurnal Variation of $\mathrm{Sq}(\mathrm{H})$ and $\mathrm{Sd}(\mathrm{H})$ for 2011's Campaign}

Diurnal variations of Sq(H) and Sd(H) during 2011's campaign are respectively plotted in Figures 8(a)-(l) and Figures 9(a)-(l). The mean monthly hourly variations of solar quiet variation were obtained by finding the mean of hourly solar quiet variation in horizontal intensity, $\mathrm{Sq}(\mathrm{H})$ for each set of the five international quiet days of each month for the year 2011. The values of $\mathrm{Sq}(\mathrm{H})$ were plotted on local time to examine the hourly variation on quiet days.

Similarly, the mean monthly hourly variation of solar disturbed variation were obtained by finding the mean of the hourly solar disturbed daily variation in horizontal intensity, $\mathrm{Sd}(\mathrm{H})$ for each set of the five international referenced disturbed days of year 2011 months. The values of $\mathrm{Sd}(\mathrm{H})$ were plotted on local time to examine the hourly variation on disturbed days.
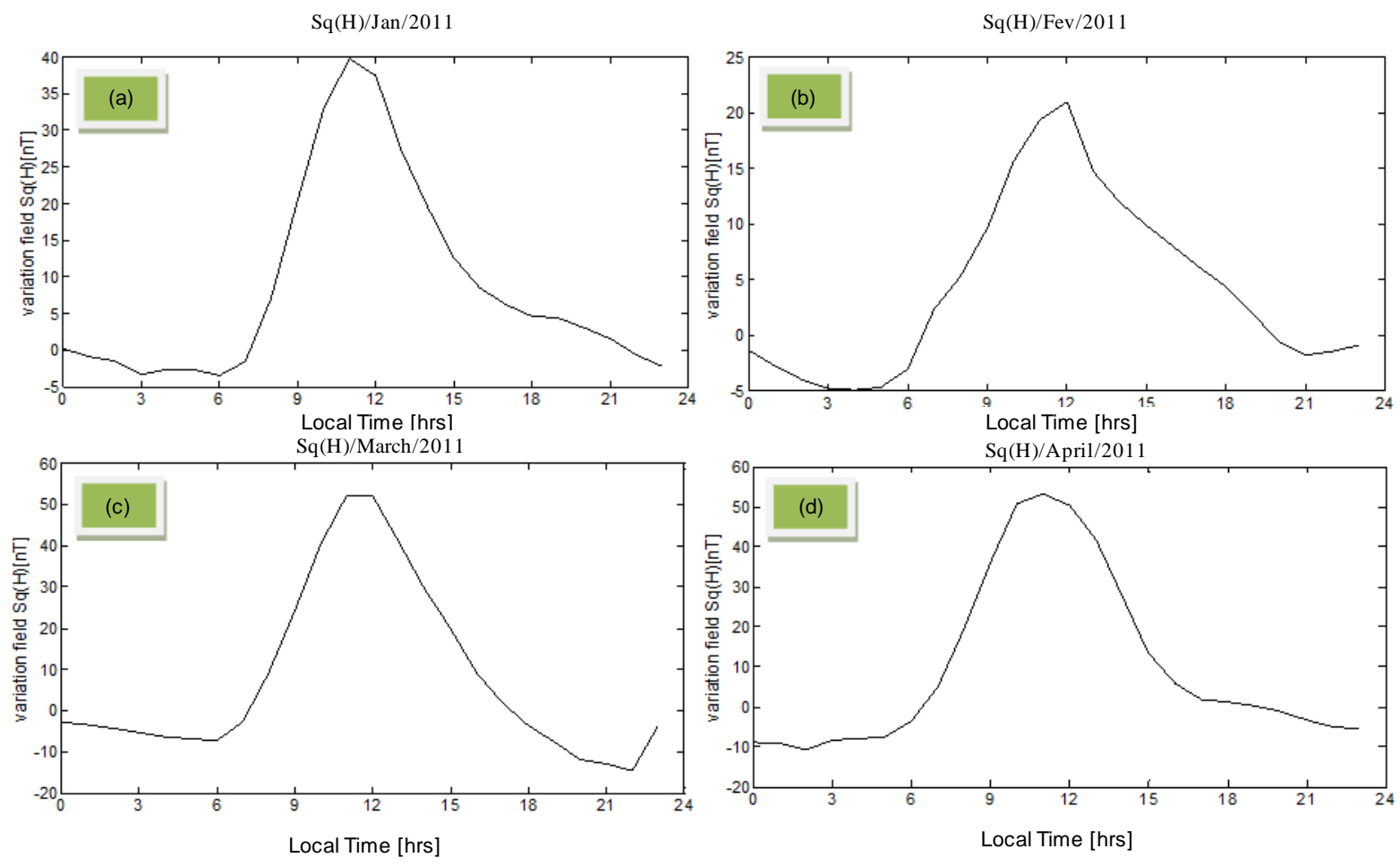

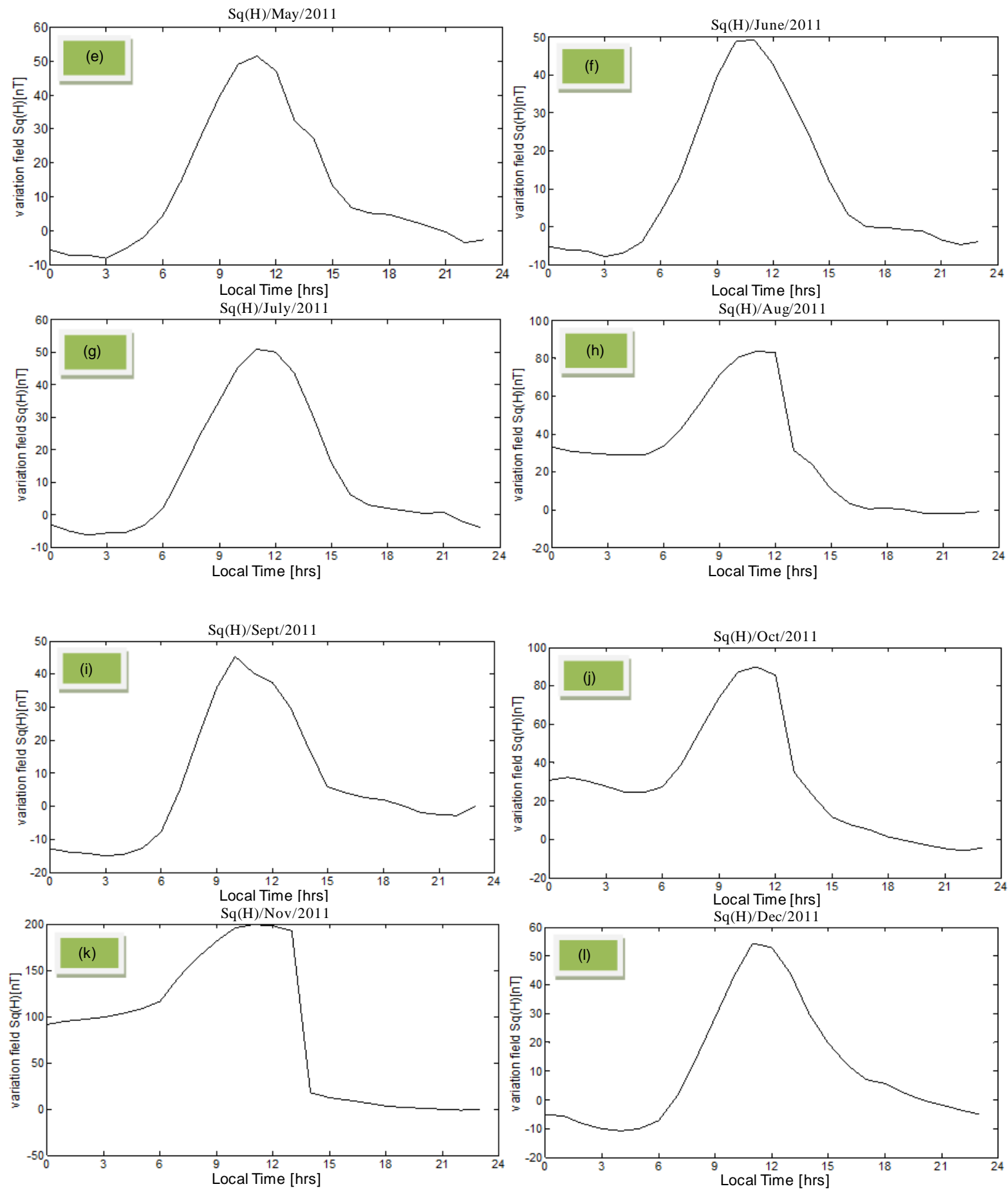

Figure 8. Diurnal variation of Sq(H) from January to December 2011.

According to both $\mathrm{Sq}(\mathrm{H})$ and $\mathrm{Sd}(\mathrm{H})$ plots, the daytime variation of $\mathrm{Sq}(\mathrm{H})$ are generally regular and smooth for all the months of the year. The diurnal variation of solar daily variation is more on the disturbed conditions than on quiet conditions. This is due to the ionospheres' disturbances originating from external drives such as space weather effects, storms, auroras etc. This confirms the results obtained by Rabiu et al. [11]. In Figures 8(a)-(l), it is observed that the scattering of variability of horizontal intensity $\mathrm{H}$ is least in January and February and greatest in August, October and November. 
The signatures of $\mathrm{Sd}(\mathrm{H})$ at Yaoundé as shown in Figures 9(a)-(I) indicate a classical rise in intensity at about the sunrise, a peak at about local noon and a gentle fall towards the sunset period. This signature of geomagnetic Sq variation in intensities is in good agreement with literature's available information [18]. It is explicable in terms of solar effects on atmospheric dynamo theory [19]. Enhanced Sq and perturbation observed in Sd could be due respectively to EEJ field and the flowing currents in the ionosphere which induce magnetic perturbations on the ground.

Variation of horizontal component field at night-time are much smaller during the night than during the day, unless for the disturbed days where the variation is more even in the night time. This confirms the consideration according to which: the ionospheres' current systems at night may be expected to be very much smaller than
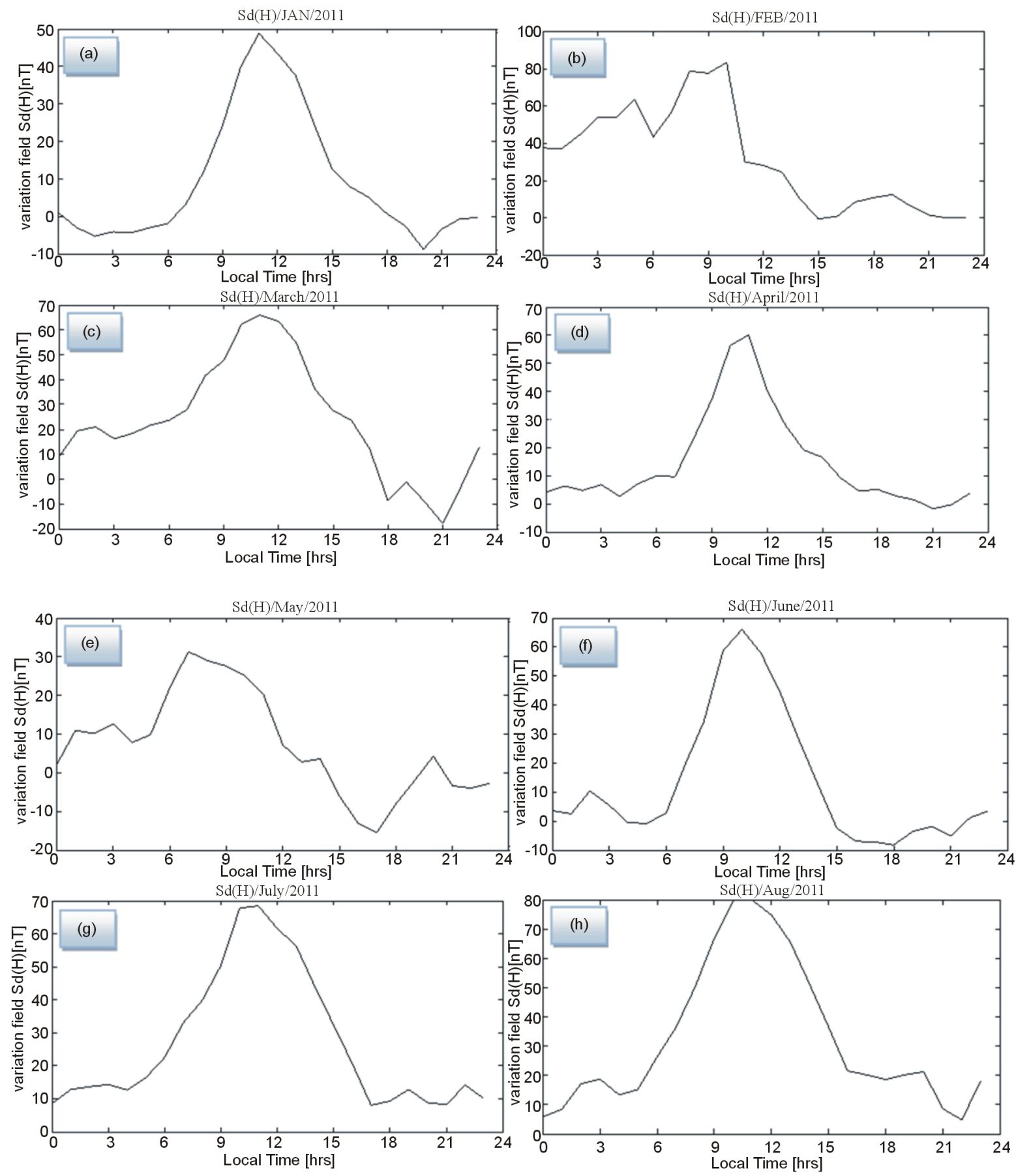

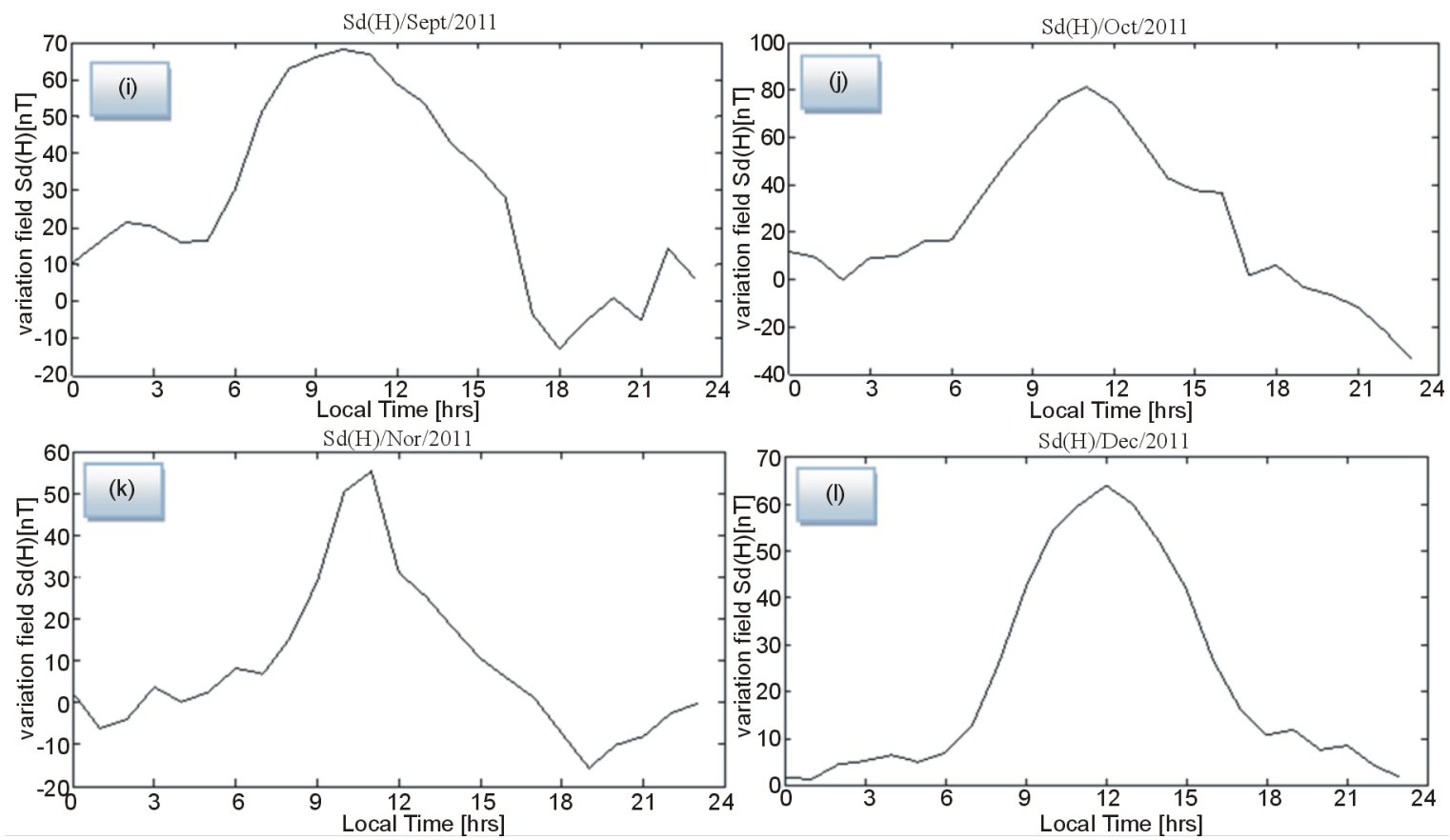

Figure 9. Diurnal variation of Sd(H) from January to December 2011.
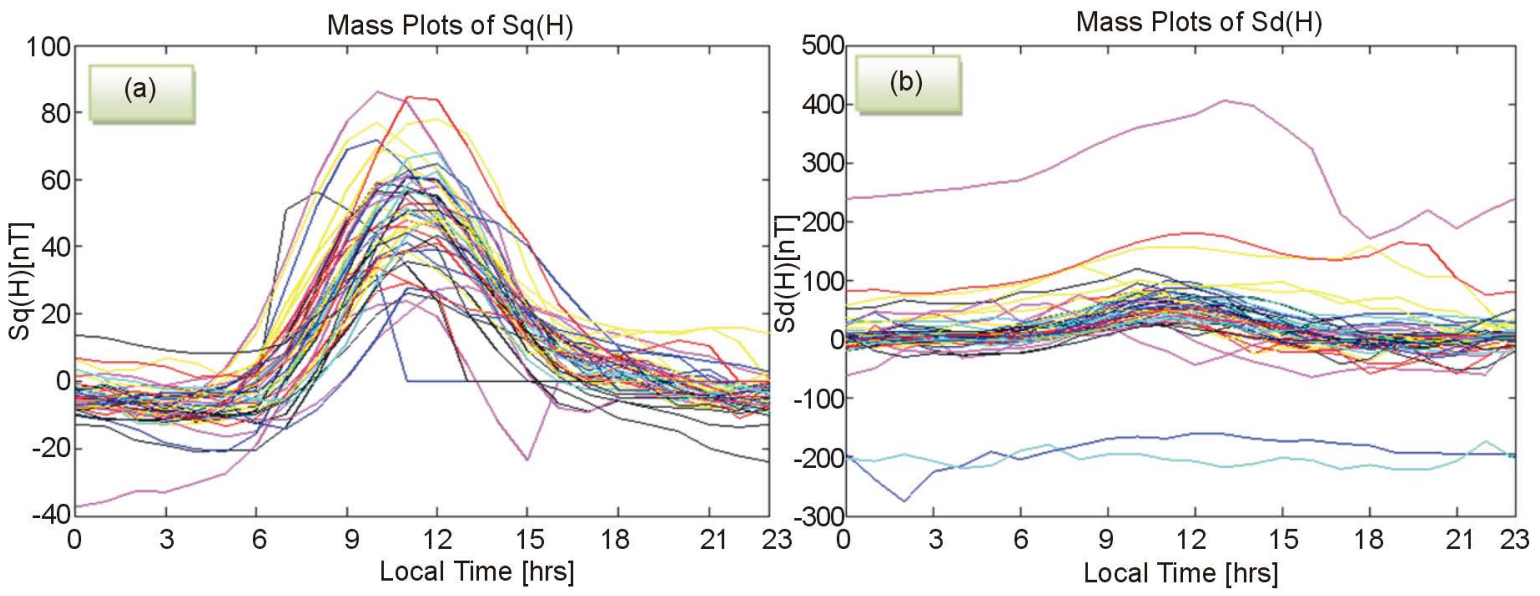

Figure 10. The mass plots of daily hourly variation of $\mathrm{Sq}(\mathrm{H})$ and $\mathrm{Sd}(\mathrm{H})$ respectively in Figure 10(a) and Figure 10(b).

those in daylight hours [12]. Also at night there are no solar radiations which should contribute to the dissociation of ions in the ionosphere. It then means that the variation observed in night might come from sources other than the ionosphere (e.g. magnetosphere, etc.) [18].

The mass plots of daily hourly variation of $\mathrm{Sq}(\mathrm{H})$ and $\mathrm{Sd}(\mathrm{H})$ drawn on Figure 10(a) \& Figure 10(b) gives a measure of day-to-day variability of the solar quiet daily variation, $\mathrm{Sq}(\mathrm{H})$ and solar disturbance daily variation $\mathrm{Sd}(\mathrm{H})$. Figure 10(a) \& Figure 10(b) also indicates that the $\mathrm{Sq}(\mathrm{H})$ and $\mathrm{Sd}(\mathrm{H})$ on one day are clearly different from $\mathrm{Sq}(\mathrm{H})$ and $\mathrm{Sd}(\mathrm{H})$ of another day even at the same hour. This implies that, there is day-to-day variability in the ionospheres' physical properties in the low latitudes region [11].

\section{Conclusions}

The results presented in this study describe the geomagnetic signatures at Yaoundé Amber Magnetometer station, and the main conclusions are the following:

1) The signatures of $\mathrm{H}$ component geomagnetic field indicate the classical rise in intensity at about sunrise, a 
peak at about local noon and a gentle fall towards sunset. The signature of geomagnetic Sq variations in intensities is explicable in terms of solar effects on the atmospheric dynamo.

2) The results indicate that the ionospheres' processes responsible for Sq variations undergo day-to-day changes.

3) All disturbances are not attributed to geomagnetic storms. They might be due to other physical processes or phenomena.

4) The scattering of variation is more in disturbed conditions than in quiet conditions. This is obviously due to ionosphere disturbances originating from external drivers, such as, space weather effects, ring currents and storms.

\section{References}

[1] Yizengaw, E. and Moldwin, M.B. (2009) African Meridian B-Field Education and Research (AMBER) Array. Earth Moon Planet, 104, 237-246. http://dx.doi.org/10.1007/s11038-008-9287-2

[2] Yizengaw, E., Moldwin, M.B., Mebrahtu, A., Damtie, B., Zesta, E., Valladares, C.E. and Doherty, P.H. (2011) Comparison of Storm Time Equatorial Ionospheric Electrodynamics in the African and American Sectors. Journal of Atmospheric and Terrestrial Physics, 73, 156-163. http://dx.doi.org/10.1016/j.jastp.2010.08.008

[3] Yizengaw, E., Moldwin, M.B., Sahai, Y. and De Jesus, R. (2009) Strong Post-Midnight Equatorial Ionospheric Anomaly Observations during Magnetically Quiet Periods. Journal of Geophysical Research, 114, Article ID: A12308. http://dx.doi.org/10.1029/2009JA014603

[4] Yizengaw, E., Retterer, J., Pacheco, E.E., Roddy, P., Groves, K., Caton, R. and Baki, P. (2013) Post-Midnight Bubbles and Scintillations in the Quiet-Time June Solstice. Geophysical Research Letters, 40, 5592-5597. http://dx.doi.org/10.1002/2013GL058307

[5] Rastogi, R.G. and Klobuchar, J.A. (1990) Ionospheric Electron Content within the Equatorial F2 Layer Anomaly Belt. Journal of Geophysical Research, 95, 19045-19052. http://dx.doi.org/10.1029/JA095iA11p19045

[6] Fejer, B.G., De Paula, E.R., Batista, I.S., Bonelli, E. and Woodman, R.F. (1989) Equatorial F Region Vertical Plasma Drifts during Solar Maxima. Journal of Geophysical Research, 94, 12049-12054. http://dx.doi.org/10.1029/JA094iA09p12049

[7] Campbell, W.H. (1997) Introduction to Geomagnetic Fields. Cambridge University Press, Cambridge.

[8] Fukushima, N. and Kamide, Y. (1973) Partial Current Models for Worldwide Geomagnetic Disturbances. Reviews of Geophysics and Space Physics, 11, 795-853. http://dx.doi.org/10.1029/RG011i004p00795

[9] Onwumechili, C.A., Matsushita, S. and Campbell, W.H. (1967) Physics of Geomagnetic Phenomena. Academic Press, New York, 425-507. http://dx.doi.org/10.1016/B978-0-12-480301-5.50014-8

[10] Obiekezie, T.N. and Agbo, G.A. (2008) Day to Day Variability of Sq(H) Variation in the Indian Sector. JANS, 3, 81-85.

[11] Rabiu, A.B., Mamukuyomi, A.I. and Joshua, E.O. (2007) Variability of Equatorial Ionosphere Inferred from Geomagnetic Field Measurements. Bulletin of the Astronomical Society of India, 35, 607-618.

[12] Agbo, G.A., Chikwendu, A.O. and Obiekezie, T.N. (2010) Variability of Daily Horizontal Component of Geomagnetic Field Component at Low and Middle Latitudes. Indian Journal of Scientific Research, 1, 1-8.

[13] Obiekezie, T.N. and Okeke, F.N. (2009) Variations of Geomagnetic H, D and Z Field Intensities on Quiet Days at West African Latitudes. Moldavian Journal of the Physical Sciences, 8, 366-372.

[14] Obiekezie, T.N. and Obiadazie, S.C. (2013) The Variability of H Component of Geomagnetic Field at the African Sector. Physical Review \& Research International, 3, 154-160.

[15] Forbes, J.M. (1981) The Equatorial Electrojet. Reviews of Geophysics, 19, 469-504. http://dx.doi.org/10.1029/RG019i003p00469

[16] Heelis, R.A. (2004) Electrodynamics in the Low and Middle Latitude Ionosphere: A Tutorial. Journal of Atmospheric and Solar-Terrestrial Physics, 66, 825-838. http://dx.doi.org/10.1016/j.jastp.2004.01.034

[17] Onwumechili, C.A. (1997) The Equatorial Electrojet. Gordon and Breach Science Publishers, the Netherlands, 610 p.

[18] Vestine, E. (1947) The Geomagnetic Field, Its Description and Analysis. Carnegie Institute, Washington Publishing, $580 \mathrm{p}$.

[19] Onwumechili, C.A. and Ezema, P.O. (1977) On the Course of the Geomagnetic Daily Variation in Low Latitudes. Journal of Atmospheric and Terrestrial Physics, 39, 1079-1086. http://dx.doi.org/10.1016/0021-9169(77)90016-2

[20] Motoba, T., Kikuchi, T., Shibata, T.F. and Yumoto, K. (2004) HF Doppler Oscillations in the Low-Latitude Ionosphere Coherent with Equatorial Long-Period Geomagnetic Field Oscillation. Journal of Geophysical Research: Space Physics, 109, Published Online. 
Scientific Research Publishing (SCIRP) is one of the largest Open Access journal publishers. It is currently publishing more than 200 open access, online, peer-reviewed journals covering a wide range of academic disciplines. SCIRP serves the worldwide academic communities and contributes to the progress and application of science with its publication.

Other selected journals from SCIRP are listed as below. Submit your manuscript to us via either submit@scirp.org or Online Submission Portal.
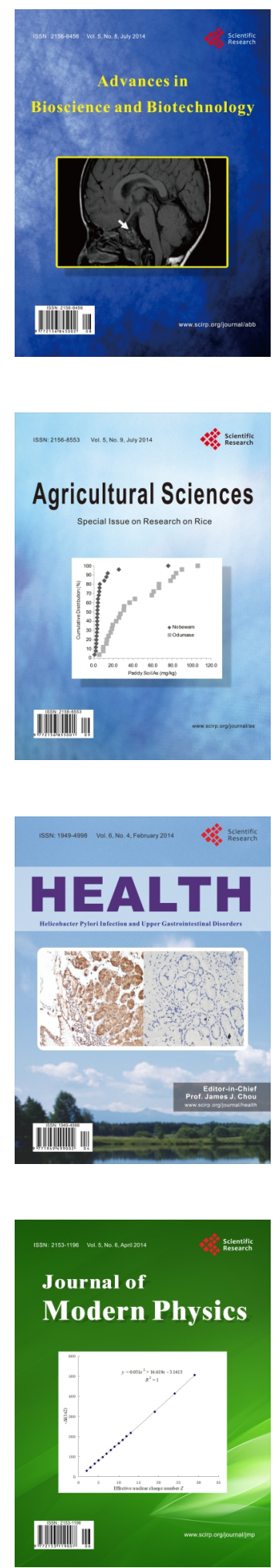
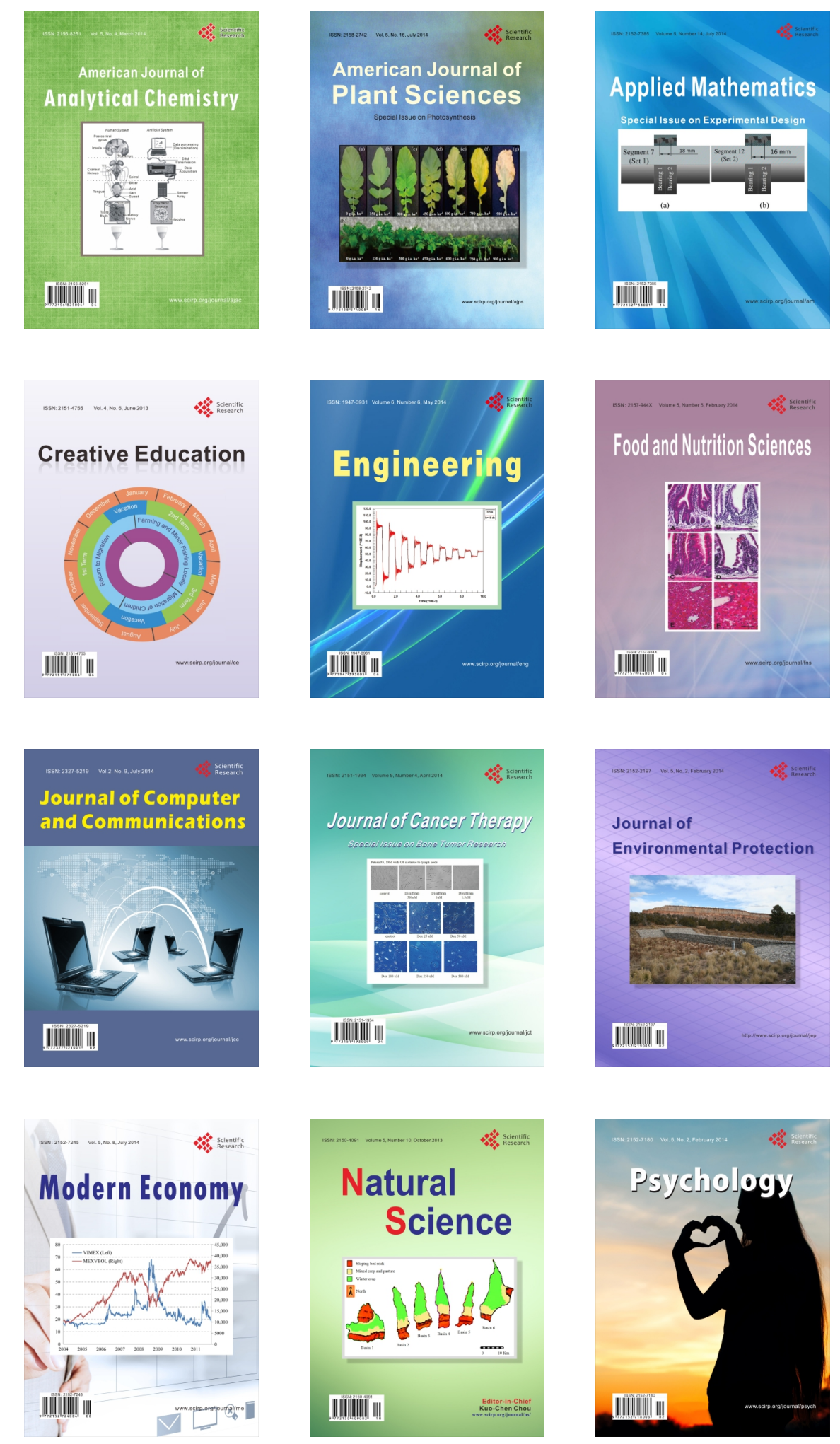